\title{
LETRAMENTO, ALFABETIZAÇÃO E LITERACIA: UM OLHAR A PARTIR DA CIÊNCIA DA LEITURA ${ }^{1}$
}

\author{
SOCIAL LITERACY, READING ACQUISITION AND LINGUISTIC LITERACY: \\ A SCIENTIFIC APPROACH TO READING
}

\section{Rosângela Gabriel²}

Recebido em: 06 de maio de 2017

Aprovado em: 27 de junho de 2017

Sistema de Avaliação: Double Blind Review

RPR | a. 14 | v. 2 | p. 76-88 | jul./dez. 2017

\section{RESUMO}

O presente artigo propõe uma reflexão sobre três conceitos - letramento, alfabetização e literacia - que estão intimamente ligados, mas que não podem ser tomados como sinônimos, uma vez que cada um guarda especificidades. Se, de um lado, o conceito de letramento vem se popularizando desde a década de 1980, com o crescente espaço a ele dedicado em livros, materiais didáticos e eventos voltados aos professores, esse crescimento não pode se dar em oposição ou em detrimento do espaço dedicado à alfabetização, uma vez que a aprendizagem inicial da leitura guarda especificidades a serem consideradas à luz dos avanços das neurociências. Por fim, se o letramento enfatiza os aspectos interativos e socioculturais envolvidos nos usos, funções e valores atribuídos à língua escrita, por outro lado, o desenvolvimento do conjunto de habilidades da leitura e da escrita (ampliação do conhecimento lexical, variação linguística e adequação ao registro, sintaxe da língua escrita, referenciação anafórica e catafórica, estabelecimentos de inferências, etc.), que constituem a literacia plena, não podem ser negligenciados, sob pena de «jogarmos fora o bebê com a água do banho».

Palavras-chave: Leitura. Escrita. Ensino de línguas. Ciências cognitivas.

\begin{abstract}
The present paper aims at discussing three concepts - social literacy, reading acquisition and linguistic literacy - which are intimately linked, but that can't be assumed as synonyms, since each one has its specificities. If, in one hand, the concept of social literacy has became more popular since the 80 's, with a broader space in books, pedagogical materials and events dedicated to school teachers, this growth should not be at the expense of the space dedicated to reading acquisition, because learning to read is a specific tool that has to be considered at the light of the neuroscience of reading's development. Finally, if social literacy emphasizes the interactive and sociocultural aspects evolved in the uses, functions and values of the written language, on the other hand, the development of a set of abilities of reading and writing (development of lexical knowledge, linguistics variation and appropriateness, written language syntax, anaphoric and cataphoric referencing, inference bridging, etc.), present in full literacy, can't be neglected, to avoid to throw the baby out with the bathwater.
\end{abstract}

Keywords: Reading. Wrting. Language teaching. Cognitive science.

\section{INTRODUÇÃO}

Como lemos? Como se dá o aprendizado inicial da leitura? Como passamos de analfabetos a leitores proficientes, capazes de compreender e interpretar textos e de aprender por meio da leitura?

\footnotetext{
${ }^{1}$ A preparação deste artigo contou com o apoio da Capes (Processo BEX 5192/14-5), da Fapergs (Edital Pesquisador Gaúcho 02/2014) e do CNPq (Processo 304883/2015-8).

${ }^{2}$ Doutora em Letras pela Pontifícia Universidade Católica do Rio Grande do Sul (Porto Alegre/Brasil). Professor na Universidade de Santa Cruz do Sul (Santa Cruz do Sul/Brasil). E-mail: rgabriel@unisc.br.
} 
Como pais, professores e responsáveis pela criação e gestão de políticas públicas voltadas à educação para a leitura podem intervir e contribuir de forma efetiva e eficaz para a criação de leitores? Essas são algumas das questões que norteiam as reflexões que serão propostas neste artigo. Desde já, prevenimos o leitor de que essas questões não serão respondidas de forma definitiva (quiçá pudéssemos responder satisfatoriamente a uma delas!), mas sua explicitação é necessária para que construamos um frame no qual possamos contextualizar as possíveis contribuições deste artigo e propor ao leitor uma perspectiva de análise de nosso objeto: a leitura e a criação de leitores (MORAIS, 2013).

Este artigo tem origem em um convite para participar do VI ENALLI - Encontro Nacional de Língua e Literatura, promovido pela Feevale, em maio de 2017. O evento se propôs a trazer contribuições relevantes aos participantes, uma vez que os temas discutidos, o letramento, a variação linguística e o ensino de línguas, são pouco debatidos com os professores que estão fora do espaço da universidade, embora estejam em voga no ambiente acadêmico. De acordo com os organizadores, o conceito de letramento(s) não é claro para os professores, a variação linguística ainda é pouco discutida em sala de aula na Educação Básica, onde o ensino de línguas continua pautado basicamente no "certo/errado" (FEEVALE, 2017). Compartilhamos com os organizadores a percepção de que o conceito de letramento(s) não está claro, talvez não só para professores, e por isso voltaremos nossa atenção para esse primeiro objeto. Propomos aqui uma reflexão sobre três conceitos - letramento, alfabetização e literacia - que estão intimamente relacionados, mas que não podem ser tomados como sinônimos, uma vez que cada um guarda especificidades que devem, necessariamente, ser consideradas no planejamento escolar e nas propostas pedagógicas voltadas à educação para a leitura. Como explicitado no título, nosso olhar está ancorado na ciência da leitura, que concebe a escrita-leitura como uma criação cultural humana com profundo impacto no processamento cognitivo, cuja flexibilidade e plasticidade permitem as reconfigurações que caracterizam o leitor proficiente.

O artigo está organizado da seguinte forma: primeiramente, convidamos o leitor a um exercício de leitura, compreensão e reflexão consciente, como se estivéssemos pensando em voz alta ou em sala de aula, conversando com nossos alunos, explorando informações textuais e extratextuais suscitadas pelo texto, dialogando com o autor por meio do texto. Num segundo momento, voltar-nos-emos ao conceito de leitura e como a amplitude desse conceito pode nos levar a "jogar fora o bebê com a água do banho"3. Propomos um zoom no processo de leitura, buscando restringir nosso olhar aos aspectos mais sutis e muitas vezes inconscientes desse processo, considerando especialmente as aprendizagens necessárias para a alfabetização. Em um terceiro momento, procuramos demonstrar que a alfabetização é o primeiro passo, mas que outros tantos passos serão necessários e decisivos para a criação de leitores autônomos. Por fim, retomaremos os três conceitos explicitados no título deste artigo, buscando definir especificidades e conexões, bem como suas implicações nas práticas pedagógicas.

\section{UM EXERCÍCIO DE LEITURA, COMPREENSÃO E REFLEXÃO}

O objetivo desta seção é promover um exercício de leitura, compreensão e reflexão, direcionando nossa atenção para aspectos do texto dos quais estamos mais ou menos conscientes quando lemos. Quando digo "estamos", refiro-me a você e eu, leitores experientes, e não a qualquer leitor. Podemos considerar esse exercício como uma espécie de "protocolo verbal escrito" (ERICSSON; SIMON, 1980;

\footnotetext{
${ }^{3}$ Alusão à expressão idiomática Don't throw the baby out with the bathwater, derivada do provérbio alemão das Kind mit dem Bade ausschütten (WIKIPEDIA, 2017), cujo sentido remete ao risco de se descuidar do essencial ao se desfazer do que não é essencial, ou ainda, de se descuidar do que é essencial, mantendo o que é acessório.
} 
1993; TOMITCH, 2007), no qual a autora deste artigo registra algumas das reflexões elicitadas pela leitura de um texto em particular.

Tomemos o texto "A boa vida", de Cláudia Laitano, publicado no jornal Zero Hora, no dia 28 de abril de 2017, sexta-feira, p. 4 (ver anexo 1). O jornal Zero Hora, cuja sede está localizada em Porto Alegre, Rio Grande do Sul, circula em versão impressa e digital. A colunista assina semanalmente a coluna de sexta-feira da página 4, espaço que abriga, nos demais dias da semana, autores como Luis Fernando Verissimo, Martha Medeiros e Carpinejar, e, na superedição de fim de semana, a carta da editora. Portanto, trata-se de um espaço nobre dentro da composição do jornal, dedicado a escritores e, no final de semana, à editora. Os textos publicados nesta coluna têm em torno de 500 palavras, e a fonte é formatada em itálico, com a foto e o nome do colunista no cabeçalho superior, contribuindo para marcar a autoria do texto e para proporcionar uma sensação de proximidade, e quiçá cumplicidade, entre autor e leitor.

O texto "A boa vida" é escrito em primeira pessoa, o que pode ser comprovado pelo uso de nossas (linha 9 e 11), temos (linha 10), li (linha 20), voltei (linha 21), fui (linha 21), oscilando entre a primeira pessoa do plural, incluindo leitor e autor em uma mesma perspectiva, e a primeira pessoa do singular, quando a autora expressa uma opinião ou perspectiva particular. O título do texto "A boa vida", retomado explicitamente no final do quarto parágrafo, é definido pela autora "numa interpretação muito singela" no quinto parágrafo: "encontrar a boa vida é descobrir qual é a sua no mundo e fazer o possível para não se perder muito nos atalhos". As reflexões sobre o tema são provocadas, segundo o texto, pelas notícias "na segunda-feira à noite" (portanto, dia 24 de abril de 2017) sobre a morte do escritor Robert M. Pirsig, autor de Zen e a Arte da Manutenção de Motocicletas (publicado em 1974).

Continuando nosso exercício de leitura, compreensão e reflexão, em que buscamos integrar informações textuais, extratextuais e intertextuais, podemos retomar as primeiras linhas do texto: "Dizem que nenhum livro muda o mundo. Livros mudam as pessoas que, com algum esforço, tentam mudar o mundo." O verbo "dizem" não apresenta no texto um sujeito gramatical explícito, mas sabemos pela terminação verbal que se trata da terceira pessoa do plural: eles, vocês, as pessoas... são palavras que poderiam concordar com o verbo na forma como está conjugado. Talvez o leitor deste artigo, assim como eu, já tenha ouvido essa frase atribuída ao escritor e poeta Mario Quintana, nascido em 1906 e falecido em 1994, em Porto Alegre, como ilustrado na Figura 1.

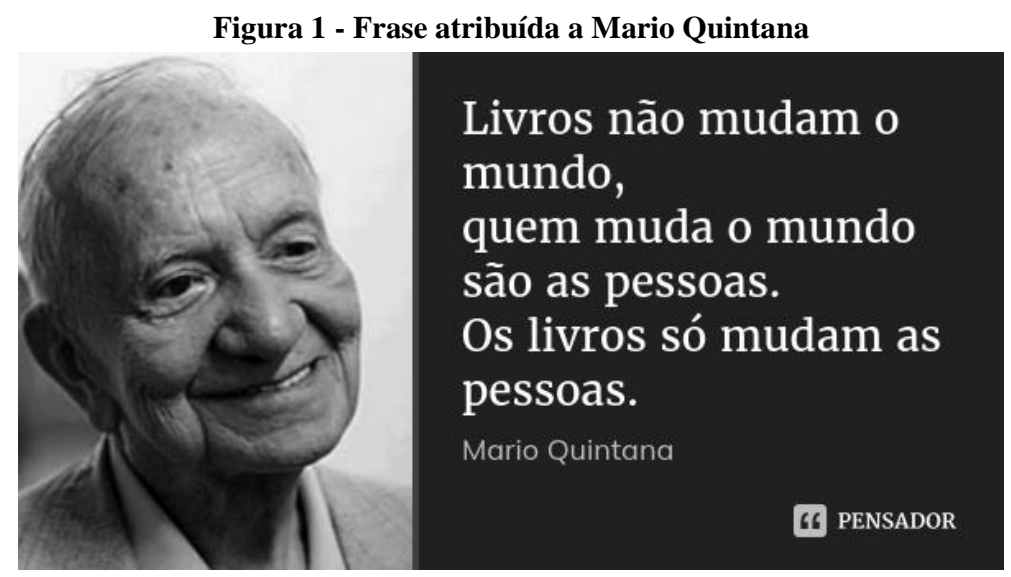

Fonte: <https://pensador.uol.com.br/frase/Njk3OTg1/>, acesso em: 24 mai. 2017

Laitano parece concordar com a afirmação, mas coloca uma objeção, introduzida pelo conectivo "no entanto" (linha 2): segundo a autora, para que o livro mude as pessoas, é preciso que dois requisitos sejam atendidos: (1) deve propor uma nova maneira de pensar ou sentir, e (2) deve chegar ao leitor no 
momento certo, nem antes nem depois. Para sustentar esse argumento, a autora utiliza um exemplo: o livro "O Segundo Sexo" (no original em francês "Le Deuxième Sexe"), de Simone de Beauvoir, publicado em 1949. De acordo com Laitano, se o livro tivesse sido escrito 50 anos antes (em 1899, portanto) talvez nem chegasse às livrarias; se fosse publicado 50 anos depois (em 1999), teria causado pouco ou nenhum impacto, ao passo que em 1949 causou uma "pequena grande revolução".

Assim como as primeiras frases do texto evocaram em minha memória uma sensação de déjá-vu e pude, com algum esforço (ou alguns cliques), recuperar a origem de quando/onde a ouvi e quem a teria dito (como ilustrado na Fig. 1), o exemplo trazido por Laitano fez pipocar referências em minha memória de longo prazo. O exemplo de um livro que causou "uma pequena grande revolução" por propor uma nova forma de pensar e por ter chegado ao leitor no momento certo, nem antes nem depois, entretanto, parece não ter sido bem escolhido. Difícil saber o que teria acontecido se "O Segundo Sexo" tivesse sido publicado em outra época. Mas afirmar que, se tivesse sido publicado cinquenta anos depois, "teria causado pouco ou nenhum impacto" implica desconhecer ou desconsiderar a polêmica causada por uma questão da prova do Exame Nacional do Ensino Médio (ENEM), de 2015, que transcreveu apenas duas frases do livro, como pode ser lido na Fig. 2.

O pequeno trecho copiado da obra de Beauvoir e abordado na questão do ENEM 2015 provocou "uma pequena grande revolução" nas redes sociais e na imprensa, com manifestações de autoridades políticas e religiosas que demonstram que o obscurantismo, que se acreditava superado, tem voz e vez no século XXI. A escritora e jornalista Eliane Brum (2015), em texto publicado no jornal El País, em 12 de novembro de 2015, expressa sua indignação diante da polêmica causada pela questão e traz uma síntese das manifestações mais contundentes relacionadas à questão do Enem e à própria Simone de Beauvoir, com hiperlinks na versão online que remetem a publicações disponíveis na internet, as quais demonstram o impacto causado pelo pequeno trecho transcrito na questão do Enem. Portanto, se as condições de recepção (ZILBERMAN, 1989) da obra "O Segundo Sexo" na metade do século passado não eram idênticas às atuais, nem por isso a obra deixa de propor uma nova maneira de pensar ou sentir ao leitor do século XXI.

Figura 2 - Questão 42 da Prova do ENEM 2015 (caderno Azul)

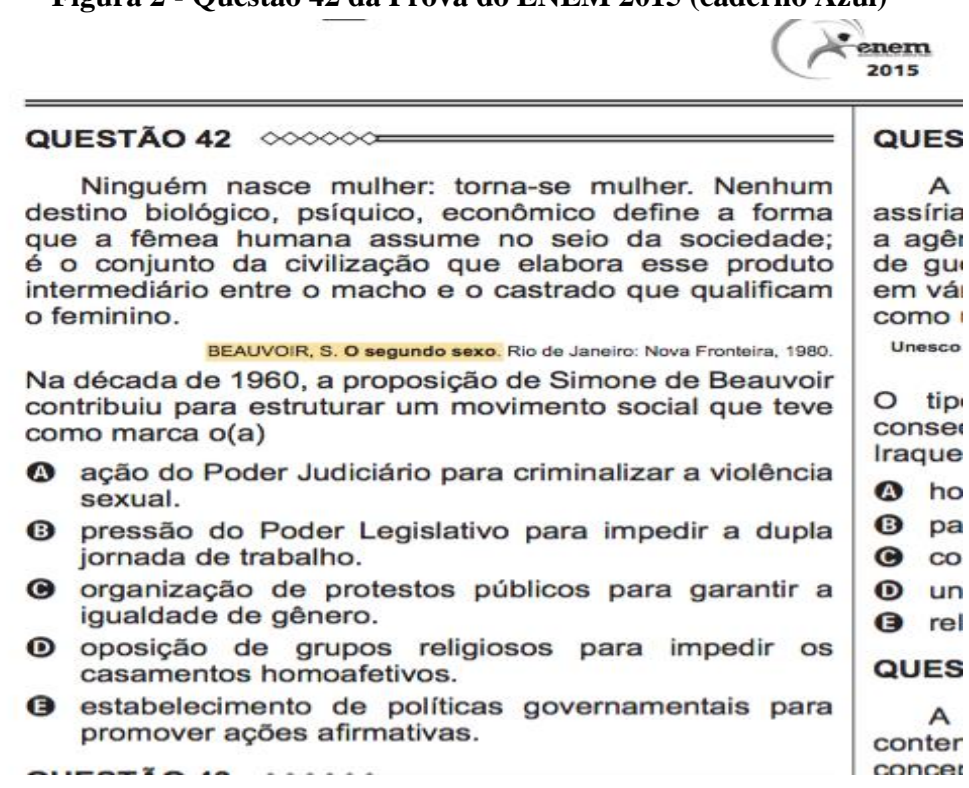

Fonte: 〈www.enem.inep.gov.br>, acesso em: 24 mai. 2017

Como nos propusemos nesta seção a um exercício de reflexão a partir da leitura do texto de Laitano, poderíamos focar nossa atenção no verbo "mudar", que aparece no texto ora conjugado, ora no 
infinitivo (linhas 1, 2, 11, 20). O significado dessa palavra é bastante abrangente. O dicionário Houaiss (2001) traz sete acepções, sendo a primeira "fazer ou sofrer mudança". A mudança ou as mudanças feitas ou sofridas poderiam, em tese, ser de diversas magnitudes, desde mudanças em microprocessos até mudanças abrangentes, como a mudança de paradigma, na acepção dada por Thomas Kuhn (1994). A acepção pretendida por Laitano considera as mudanças no "mundinho íntimo" de cada leitor (linha 8), provocadas por livros que podem ficar na memória tanto pelo impacto estético quanto pela "sensação de Queda da Bastilha interior". Essas mudanças parecem fazer referência ao sistema de valores subjetivo que norteia nossas escolhas e decisões mais ou menos conscientes. Entretanto, há uma dimensão da leitura, de livros ou de outros textos escritos, que causa mudanças profundas na forma de pensar do leitor e que são de natureza distinta. É para a dimensão cognitiva da leitura, muitas vezes inconsciente, que queremos direcionar nossa atenção na próxima seção.

\section{A LEITURA MUDA AS PESSOAS}

O editorial da revista Brain (v. 121, 1998), assinado por Uta Frith, começa com uma instigante pergunta: Pode a cultura modificar a anatomia básica do cérebro? Ao longo das últimas décadas, vários estudos vêm demostrando que as alterações comportamentais decorrentes do aprendizado da leitura correlacionam-se com alterações na anatomia cerebral e na forma como nosso cérebro processa informações (MORAIS et al., 1979; CASTRO-CALDAS et al., 1998; DEHAENE et al., 2010; 2015; MONZALVO; DEHAENE-LAMBERTZ, 2013). Frith (1998) afirma que a cultura modifica o cérebro, uma vez que a aprendizagem da leitura modifica a forma como a linguagem verbal é processada. Quais seriam as mudanças no processamento da linguagem verbal decorrentes da aprendizagem da leitura? Além da linguagem verbal, que outras habilidades cognitivas são afetadas pela aprendizagem da leitura?

Comecemos lembrando que a leitura é um artefato cultural, presente em algumas culturas, mas não em todas: houve e há sociedades ágrafas, que não desenvolveram sistemas de escrita; houve e ainda há adultos analfabetos convivendo em sociedades letradas; via de regra, as crianças aprendem a ler no segundo quinquênio de vida, sob a orientação de professores e da educação formal e sistemática. Portanto, desde já, é fundamental perceber que, ainda que a leitura e a escrita sejam usos particulares da linguagem, sua aprendizagem não pode ser equiparada ao processo de aquisição da linguagem oral, presente em todos os grupos humanos.

Os processos cognitivos que nos conduzem à compreensão leitora são de natureza consciente e inconsciente, e os níveis de consciência das diversas camadas linguísticas (fonológica, morfológica, semântica, sintática, pragmática) são distintos em leitores aprendizes e em leitores maduros, assim como em não leitores. Morais et al. (1979) foram pioneiros ao demonstrar que iletrados têm um desempenho pífio em tarefas que requerem consciência fonológica como, por exemplo, deletar o primeiro fonema da palavra "porto", resultando em "orto". Crianças antes da alfabetização apresentam o mesmo comportamento. Assim, os autores concluem que a habilidade de manipular explicitamente os fonemas não é adquirida espontaneamente, mas é uma consequência sine qua non da aprendizagem da leitura em sistemas alfabéticos, uma vez que para ler e escrever o aprendiz precisará quebrar os sons da fala em suas partes constituintes.

O mesmo comportamento observado em iletrados adultos é apresentado por crianças antes da alfabetização. Crianças e adultos analfabetos são capazes de suprimir sílabas, por exemplo, /ka/ de /'kaza/, resultando /za/, mas o mesmo não se observa quanto à supressão do fonema inicial /k/. Portanto, o uso da linguagem verbal oral não implica análise e consciência dos fonemas constituintes das palavras. Essa consciência pode e deve ser estimulada no período anterior à alfabetização, como uma forma de 
auxiliar a criança e o adulto iletrado a analisarem a linguagem verbal oral em suas unidades fonológicas constituintes, para então estarem mais bem preparados para estabelecerem a associação entre os fonemas (unidades da oralidade) e os grafemas (unidades da escrita) (STANOVICH; CUNNINGHAM; CRAMER, 1984; MORAIS, et al., 1986; ADAMS et al., 2006; LAMPRECHT, 2009). Uma vez que a criança ou o adulto estejam alfabetizados, a consciência fonológica será continuamente requerida para a leitura e escritura de palavras novas ou de baixa frequência, quando o leitor não puder lançar mão da memória de sequências ortográficas (MORAIS; LEITE; KOLINSKY, 2013). Assim, a leitura e a escritura reforçam continuamente a habilidade de análise fonológica naqueles que dominam e praticam essas habilidades, ao ponto de nós, leitores, ficarmos surpresos por crianças e analfabetos não serem capazes de segmentar palavras em seus fonemas constituintes!

Outra mudança decorrente da aprendizagem da leitura são as alterações no tratamento visual, ou seja, na forma como vemos as palavras e as imagens. Estudos de neuroimagem em crianças normais e disléxicas mostram que, com a aquisição da leitura, uma área específica do cérebro no córtex occípito temporal esquerdo - a visual word form area (VWFA) ou área da forma visual da palavra - passa a responder ao estímulo ortográfico de palavras aprendidas (MONZALVO et al., 2012). As informações percebidas por nossos olhos direcionam-se à parte posterior do cérebro, na região occipital. Entretanto, a medida que aprende a ler, o cérebro se reorganiza, dedicando parte de seus recursos para o processamento da linguagem verbal escrita (DEHAENE; COHEN, 2007; DEHAENE et al. 2010; DEHAENE et al., 2015).

O fato de haver uma demanda por especialização de uma região cerebral para o tratamento do material de leitura faz com que outras regiões tenham que se reorganizam e concentrar sua atividade em uma região mais circunscrita do córtex, ganhando com isso eficiência. A dispersão de informação no cérebro não é sinônimo de eficiência; ao contrário, há um princípio de economia: mais desempenho com menos esforço. Assim, parece haver uma especialização por categoria de objetos no córtex ventral visual em letrados (letras, casas, faces etc.), constituindo um mosaico que se complementa. Por outro lado, no estudo desenvolvido por Dehaene et al. (2010), a comparação das respostas para categorias de objetos, como "casas" por exemplo, mostrou diferença entre aqueles que viveram/vivem em zonas rurais vs. zonas urbanas, mostrando um efeito de familiaridade e a importância da cultura sobre nossas respostas aos estímulos. Assim, neste caso, nem o desempenho em leitura nem a escolaridade, mas sim as experiências culturais dos sujeitos fizeram com que reconhecessem as imagens mostradas como casas (na verdade, as imagens das casas lembravam casas urbanas de classe média-alta, e não casas típicas de moradores da zona rural ou da periferia dos centros urbanos).

A aprendizagem da leitura modifica nossa memória, tanto a memória de longo prazo, quanto a memória de processamento imediato. Assim como na relação entre consciência fonológica e aprendizado da leitura, há uma complexa relação de causa e efeito entre memória e leitura, pois a maior capacidade (span) da memória de trabalho é um facilitador da aprendizagem da leitura; ao mesmo tempo, aprender a ler modifica as representações mentais na memória do letrado. Portanto, a aprendizagem cultural, no caso a leitura, age sobre o componente cognitivo mais primitivo, a memória, promovendo mudanças em ambas as direções, a tal ponto que causa e efeito se fundem.

Uma das mudanças provocadas pela aprendizagem da leitura vem da necessidade de analisar a linguagem oral, que motiva o desenvolvimento da reprodução subvocal (repetir a palavra mentalmente, sem produção de som, mas com ativação das regiões cerebrais, inclusive motoras, responsáveis pela emissão vocal), o que promove o desenvolvimento da memória serial, ou seja, não apenas lembrar de itens de forma aleatória, mas lembrar de uma sequência de itens na ordem em que se apresentam (DEMOULIN; KOLINSKY, 2015). A linearidade é uma característica tanto da linguagem oral quanto 
da linguagem escrita e a ordem em que os fonemas e grafemas se apresentam ativam significados distintos, como na sequência "tapa" e "pata". Portanto, na linguagem verbal, a ordem dos fatores altera o produto! A necessidade contínua de análise serial requerida pela leitura e escrita treina nosso cérebro para prestar atenção na ordem serial em que os elementos se apresentam.

Ler e escrever em sistemas alfabéticos, como já dissemos, promove a emergência da consciência fonológica, que por sua vez refina as representações mentais dos fonemas e agrega uma representação ortográfica à rede de conhecimentos disponível no léxico mental. Essas representações envolvem vários tipos de memória, incluindo a memória motora, no caso na escrita, em especial da manuscrita, e da memória visual, no caso da leitura (LONGCAMP; ZERBATO-POUDOU; VELAY, 2005; KOLINSKY; PATTAMADILOK; MORAIS, 2012). Esse incremento na qualidade, força e precisão das representações lexicais dá suporte à codificação de novos itens na memória de longo prazo e cria novas chaves de acesso à rede de informações armazenadas na memória, quando da necessidade de evocação (KOLINSKY, 2015).

Poderíamos continuar explorando as descobertas realizadas nas últimas décadas pelos pesquisadores que estudam a leitura pelo viés cognitivo, destacando argumentos que permitem afirmar que a leitura muda as pessoas, ainda que em aspectos dos quais não temos consciência ou temos consciência apenas parcial (DEHAENE, 2014). Entretanto, este artigo, coerente com a apresentação realizada durante o VI ENALLI, propõe-se a refletir sobre o ensino de línguas, em especial sobre os conceitos de letramento, alfabetização e literacia. É para essa direção que voltaremos nossa atenção na próxima seção, procurando articular perspectivas e construir uma visão abrangente para o desafio de contribuir para a criação de leitores autônomos.

\section{LETRAMENTO, ALFABETIZAÇÃO OU LITERACIA?}

Na seção anterior, destacamos a importância da consciência fonológica para a aprendizagem da leitura e para a representação refinada do conhecimento lexical armazenado na memória. Nesta seção, propomos inicialmente um exercício para o desenvolvimento da consciência lexical, ou melhor, um exercício para pensarmos detidamente no que as palavras letramento, alfabetização e literacia significam, e para as consequências que uma representação difusa de conceitos relevantes como esses pode ter para a prática pedagógica.

Em artigo publicado em 2016, Gabriel, Kolinsky e Morais propõem uma reflexão sobre o conceito de leitura, buscando evitar estender o objeto de estudo, a fim de apreender o que ele tem de específico, de intrinsecamente interessante. Para tanto, apresentam uma minuciosa análise de aspectos compartilhados entre linguagem oral e escrita, em oposição a aspectos que distinguem essas modalidades (ver Quadros 1 e 2, p. 925). Se nosso olhar é pedagógico, saber se as dificuldades apresentadas pelos alunos na leitura são decorrentes do pouco conhecimento linguístico ou da falta de referências culturais faz muita diferença, pois nossa intervenção pedagógica poderá ser guiada por um diagnóstico mais fidedigno e, espera-se, mais eficiente.

Raciocínio análogo pode ser desenvolvido quando se trata do conceito de letramento. Fala-se hoje em letramento digital, letramento literário, letramento científico, letramento matemático, letramento visual... O que a palavra letramento significa em cada uma das adjetivações que recebe? O que há de comum nessas expressões?

Soares (2016, p. 28-29) reserva o termo letramento para dar conta de duas facetas da inserção do indivíduo no mundo da escrita: a faceta interativa, que concebe a língua escrita como veículo de interação entre pessoas, e a faceta sociocultural, que considera os usos, funções e valores atribuídos à 
escrita em contextos socioculturais. Parece-nos que o caráter de iniciação é um dos traços semânticos comum aos vários usos do termo letramento. Assim, o processo de inserção no mundo da escrita, nos ambientes digitais, nos textos literários, etc, é evocado pelo termo letramento, com a devida adjetivação. Outro aspecto inerente ao conceito de letramento diz respeito aos usos, funções e valores socioculturais da escrita, das ferramentas digitais, do texto literário, do conhecimento científico e matemático, da interpretação das imagens... Portanto, podemos dizer que os aspectos interativos e socioculturais de várias práticas são evocadas pelo termo letramento, ao passo que o adjetivo que o acompanha dá conta do "universo" no qual o indivíduo será inserido. Por outro lado, sem adjetivação, letramento dá conta da inserção do indivíduo no mundo letrado, não o do beletrismo ou das "belas letras", mas em uma sociedade que se organiza a partir de uma gama de gêneros textuais com inúmeras finalidades. Assim, adotar a perspectiva pedagógica do letramento implicaria preparar os alunos para a participação efetiva e competente nas práticas sociais e profissionais que envolvem a língua escrita.

Mas como preparar os alunos para essa participação efetiva e competente? Por onde começar?

Por onde continuar? Podemos começar pela leitura compartilhada na família e na escola, desde os primeiros meses de vida do bebê e ao longo de todo o desenvolvimento infantil, como propõem Gabriel e Morais (2017). De acordo com os autores, a leitura compartilhada realizada entre o adulto e a criança(s) contribui para o desenvolvimento das habilidades linguísticas necessárias à leitura autônoma, cujo objetivo final pode ser a compreensão, aprendizagem, fruição, etc.

Por onde avançar? Sem dúvida, um dos marcos para a participação efetiva e competente nas práticas sociais e profissionais que envolvem a língua escrita é a alfabetização, ou seja, o período de um, dois ou três anos durante os quais se desenvolve a consciência fonológica, que permite a quebra da linguagem oral em suas partes constituintes, ou seja, os fonemas, e o conhecimento das letras e dos grafemas, com a necessária associação entre os fonemas e os grafemas que os representam. O período de alfabetização compreende ainda a construção de representações ortográficas das palavras, o que possibilitará a fluência na leitura, graças à automatização da relação entre sequências ortográficas e a imagem acústica armazenada na memória. Sem essa automatização, é impossível chegar à compreensão de textos, pois nossa memória de trabalho é limitada (GABRIEL et al., 2016 a ), e se decodificarmos grafema por grafema, teremos esquecido o que lemos no início da frase quando chegarmos ao ponto final. Aprender a ler em uma escrita alfabética não tem nada de simples. Trata-se de uma aprendizagem complexa, que exige que nosso cérebro se adapte a essa criação cultural e recicle os recursos cognitivos disponíveis. As especificidades da alfabetização exigem a intervenção de profissionais preparados, que conheçam os aspectos linguísticos e cognitivos envolvidos e assim possam auxiliar os alunos a enfrentarem as inúmeras dificuldades desse processo (SCLIAR-CABRAL, 2013; DEHAENE et al., 2011; MALUF; CARDOSO-MARTINS, 2013).

Por onde continuar? Pelo desenvolvimento da literacia! O termo literacia é importado da literatura anglo-saxônica (literacy) e diz respeito ao "conjunto das habilidades da leitura e da escrita (identificação das palavras escritas, conhecimento da ortografia das palavras, aplicação aos textos dos processos linguísticos e cognitivos de compreensão)" (MORAIS, 2013, p. 4). Na literatura de língua inglesa, o termo literacy não se confunde com a aprendizagem inicial da leitura, que é denominada reading acquisition, reading instruction, beginning litteracy, campo de estudos que trata dos processos cognitivos e da intervenção pedagógica cujo objetivo é auxiliar o aluno nessa aprendizagem. Ainda que aprender a ler seja um marco no desenvolvimento da competência comunicativa por meio da leitura e da escrita, outras aprendizagens serão necessárias na criação de leitores competentes. Uma delas diz respeito ao desenvolvimento do vocabulário. O conhecimento do vocabulário é uma das variáveis preditivas da compreensão textual, ou seja, quanto maior o número de palavras conhecidas, maior a 
chance de compreender um determinado texto (NATION; SNOWLING, 2004; SOUSA; GABRIEL, 2011). Por outro lado, é a compreensão textual que permite a aprendizagem por meio da leitura, pois as limitações de nossa memória, em geral, não permitem que armazenemos cada uma das palavras do texto, mas sim as principais ideias que compreendemos a partir da leitura dos textos (KINTSCH, 1998). Além disso, há uma série de microprocessos envolvidos na construção do tecido textual (uso de conectivos, tempos verbais, processos de referenciação anafórica e catafórica, etc.) que necessitam da intervenção pedagógica para que sejam devidamente reconhecidos e manipulados, de acordo com os objetivos do leitor-autor, a fim de que o estudante possa desenvolver a competência linguística ao longo dos anos escolares (GABRIEL et al., 2016 b).

Portanto, letramento, alfabetização e literacia não são conceitos excludentes, não competem entre si, mas também não se confundem. Não se trata de "ou isto, ou aquilo", mas sim de "isto, aquilo e mais aquilo", ou seja, perspectivas complementares de um objeto complexo. Ainda que essa especificidade e complementaridade pareçam óbvias, elas precisam ser reiteradas, pois no Brasil parece ter se instalado uma rivalidade inexplicável entre perspectivas sociais e cognitivas da leitura, como atestam Soares (2004) e Morais (2013), o que só vem em prejuízo de estudantes e professores. Nosso objetivo ao discutir esses conceitos foi justamente buscar entender as contribuições que cada uma dessas perspectivas tem a dar para a ação pedagógica.

\section{CONSIDERAÇÕES FINAIS}

Um juiz de Direito, quando acionado pelas partes por meio de um processo, precisa julgá-lo, amparado na legislação e na jurisprudência existente. Não é possível dizer: "este processo é muito difícil, não vou julgá-lo". Um professor de línguas, quando prepara suas aulas, precisa pensar nos objetivos que pretende alcançar e na melhor intervenção pedagógica para dar conta desses objetivos. Não é possível dizer: "estes alunos não sabem o que eu esperava que soubessem, não vou ensiná-los". Cabe ao professor, em cada contexto escolar, partir do que os alunos já sabem e levá-los a conhecer o que ainda não sabem. Sem dúvida, o desenvolvimento da competência em leitura é um dos grandes objetivos da escolarização. O que o professor pode fazer para alavancar o desenvolvimento dessa competência?

Em um país como o Brasil, com grandes diferenças socioeconômicas, com uma população que só nas últimas décadas chegou à escola, com altos índices de analfabetismo funcional, essa pergunta é ainda mais contundente. Inúmeras pesquisas mostram que a escolaridade dos pais, em especial das mães, tem influência no desempenho em leitura das crianças; que o número de livros disponíveis em casa é um indicador importante do desempenho escolar; que o stress crônico decorrente da pobreza e da insegurança social produz efeitos negativos no desenvolvimento cognitivo e na esperança de vida (MORAIS, 2014). Por todas essas razões, o papel da escola e do professor é ainda mais importante. Muitos de nossos alunos só poderão contar conosco no desenvolvimento da competência em leitura.

Neste artigo, propusemos um exercício de leitura, compreensão e reflexão de um texto, no caso a coluna de Cláudia Laitano, a fim de exemplificar alguns aspectos que devem ser observados na condução da leitura mediada com os alunos, tais como o suporte, o gênero, a autoria, o contexto do jornal no qual o texto é veiculado, a intertextualidade, as referências que podem ou devem ser buscadas, as possibilidades de contra-leitura ou contra-argumentação... Na seção seguinte, procuramos explorar algumas das descobertas da ciência da leitura. Ainda que, enquanto leitores não tenhamos consciência de inúmeros processos que acontecem quando lemos, na condição de professores precisamos estar conscientes das mudanças ocorridas ou que estão ocorrendo no cérebro-mente de nossos alunos, a fim de compreender as dificuldades e poder intervir, a fim de transpor obstáculos ao desenvolvimento da 
competência leitora. Por fim, a última seção teve por objetivo refletir sobre três conceitos que merecem a atenção de professores e daqueles que pensam a escola e as políticas públicas, a fim de que uma visão difusa não nos faça descuidar do que é de fato relevante.

\section{REFERÊNCIAS}

ADAMS, M. J. Consciência fonológica em crianças pequenas. Porto Alegre: Artmed, 2006, 215p.

BRASIL. ENEM - Exame Nacional do Ensino Médio. Disponível em: <http://enem.inep.gov.br〉. Acesso em: 30 mai. 2017.

BRUM, E. Parabéns, atingimos a burrice máxima. EL PAÍS Brasil, 12 novembro 2015. Opinião. Disponível em: <http://brasil.elpais.com/brasil/2015/11/09/opinion/1447075142_888033.html>. Acesso em: 25 mai. 2017.

CASTRO-CALDAS, A.; PETERSSON, K. M.; REIS, A.; STONE-ELANDER, S.; INGVAR, M. The illiterate brain. Learning to read and write during childhood influences the functional organization of the adult brain. Brain, 121, p. 1053-1063, 1998.

DEHAENE, S.; COHEN, L. Cultural recycling of cortical maps. Neuron, 56, p. 384-398, 2007.

DEHAENE, S.; PEGADO, F.; BRAGA, L. W.; VENTURA, P.; NUNES FILHO, G.; JOBERT, A.; DEHAENE-LAMBERTZ, G.; KOLINSKY, R.; MORAIS, J.; COHEN, L. How Learning to Read Changes the Cortical Networks for Vision and Language. Science, 330, p. 1359-1364, 2010.

DEHAENE, S.; DEHAENE-LAMBERTZ, G.; GENTAZ, E.; HURON, C.; SPRENGERCHAROLLES, L. Apprendre à lire: des sciences cognitives à la salle de classe. Paris: Odile Jacob, 2011.

DEHAENE, S. Consciousness and the brain: deciphering how the brain codes our thoughts. New York: Viking, 2014.

DEHAENE, S.; COHEN, L.; MORAIS, J.; KOLINSKY, R. Illiterate to literate: behavioral and cerebral changes induced by reading acquisition. Nature Reviews Neuroscience, 16, p. 234-244, 2015.

DEMOULIN, C; KOLINSKY, R. Does learning to read shape verbal working memory? Psychonomic bulletin \& review, Advance online publication. Publié, 2015-10-05.

ERICSSON, K. A.; SIMON, H. A. Verbal reports as data. Psychological Review, v. 87, p. 215-251, 1980.

ERICSSON, K. A.; SIMON, H. A. Protocol analysis. Verbal reports as data [revised edition]. Cambridge: MIT Press, 1993.

FEEVALE. VI ENALLI - Encontro Nacional de Língua e Literatura. Disponível em: $<$ http://www.feevale.br/cursos-e-eventos/vi-encontro-nacional-de-lingua-e-literatura $>$. Acesso em: 30 mai. 2017.

FRITH, U. Editorial: Literally changing the brain. Brain, 121, issue 6, p. 1011-1012, 1998.

GABRIEL, R.; MORAIS, J. A leitura compartilhada, na família e na escola. In: FLÔRES, O. C.;

GABRIEL, R. O que pais e professores precisam saber sobre leitura? Contribuições

interdisciplinares. Santa Maria: Editora UFSM, 2017. p. 23-48. 
GABRIEL, R.; MORAIS, J.; KOLINSKY, R. A Aprendizagem da leitura e suas implicações sobre a memória e a cognição. Ilha do Desterro/UFSC, v. 69, n.1, p. 61-78, 2016 a.

GABRIEL, R.; KOLINSKY, R.; MORAIS, J. O milagre da leitura: de sinais escritos a imagens imortais. D.E.L.T.A., 32.4, p. 919-951, 2016b.

HOUAISS, A.; VILLAR, M. de S. Dicionário Houaiss da Língua Portuguesa. Rio de Janeiro: Objetiva, 2001.

KINTSCH, W. Comprehension: a paradigm for cognition. Cambridge, UK: Cambridge University Press, 1998.

KOLINSKY, R.; PATTAMADILOK, C.; MORAIS, J. The impact of orthographic knowledge on speech processing. Ilha do Desterro/UFSC, n. 63, p. 161-186, 2012.

KOLINSKY, R. How Learning to Read Influences Language and Cognition. In: POLLATSEK, A.; TREIMAN, R (eds.). The Oxford Handbook of Reading. Oxford: Oxford University Press, 2015. p. 377-396.

KUHN, T. Estrutura das revoluções científicas. São Paulo: Perspectiva, 1994.

LAITANO, C. A boa vida. Zero Hora, 20/abril/2017, p. 4.

LAMPRECHT, R (Org.) Consciência dos sons da língua: subsídios teóricos e práticos para alfabetizadores, fonoaudiólogos e professores de língua inglesa. Porto Alegre: EDIPUCRS, 2009.

LONGCAMP, M.; ZERBATO-POUDOU, M.-T.; VELAY, J.-L. The influence of writing practice on letter recognition in preschool children: a comparison between handwriting and typing. Acta Psychologica, v.119, p. 67-79, 2005.

MALUF, M. R.; CARDOSOS-MARTINS, C. Alfabetização no século XXI - como se aprende a ler e escrever. Porto Alegre: Penso, 2013. 183p.

MONZALVO, K.; FLUSS, J.; BILLARD, C.; DEHAENE, S.; DEHAENE-LAMBERTZ, G. Cortical networks for vision and language in dyslexic and normal children of variable socio-economic status. NeuroImage, 61, p. 258-274, 2012.

MORAIS, J.; CARY, L.; ALEGRIA, J.; BERTELSON, P. Does awareness of speech as a sequence os phones arise spontaneously? Cognition, 7, p. 323-331, 1979.

MORAIS, J.; BERTELSON, P.; CARY, L.; ALEGRIA, J. Literacy training and speech segmentation. Cognition, 24, p. 45-64, 1986.

MORAIS, J. Criar leitores: para professores e educadores. São Paulo: Manole, 2013.

MORAIS, J.; LEITE, I.; KOLINSKY, R. Entre a pré-leitura e a leitura hábil: condições e patamares de aprendizagem. In: MALUF, M. R.; CARDOSO-MARTINS, C. Alfabetização no século XXI: como se aprende a ler e a escrever. Porto Alegre: Penso, 2013.

MORAIS, J. Alfabetizar para a democracia. Porto Alegre: Penso, 2014.

NATION, K.; SNOWLING, M. Beyond phonological skills: broader language skills contribute to the development of Reading. Journal of Research in Reading, v.27, Issue 4, 2004, p 342-356.

SCLIAR-CABRAL, L. Sistema Scliar de alfabetização. Florianópolis: Lili, 2013. 
SOARES, M. Letramento e alfabetização: as muitas facetas. Revista Brasileira de Educação, n. 25, p. 5-17, jan-abril 2004.

SOARES, M. Alfabetização: a questão dos métodos. São Paulo: Contexto, 2016.

SOUSA, L. B.; GABRIEL, R. Aprendendo palavras através da leitura. Santa Cruz do Sul: EDUNISC, 2011, v.01. p.135.

STANOVICH, K.; CUNNINGHAM, A. E.; CRAMER, B. B. Assessing Phonological Awareness in Kindergarten Children: Issues of Task Comparability. Journal of Experimental Child Psychology, n. 38, p. 175-190, 1984.

TOMITCH, L. M. B. Desvelando o processo de compreensão leitora: protocolos verbais na pesquisa em leitura. Signo, Santa Cruz do Sul, v. 32, n. 53, p. 42-53, jul. 2007. ISSN 1982-2014. Disponível em: 〈https://online.unisc.br/seer/index.php/signo/article/view/244>. Acesso em: 25 mai. 2017.

ZILBERMAN, R. Estética da recepção e história da literatura. São Paulo: Ática, 1989.

WIKIPEDIA. Disponível em:

<https://en.wikipedia.org/wiki/Don\%27t_throw_the_baby_out_with_the_bathwater>. Acesso em: 30 mai. 2017. 


\section{ANEXO}

\section{A boa vida}

Cláudia Laitano

\begin{tabular}{|c|l|l|}
\hline 1 & $\begin{array}{l}\text { Dizem que nenhum livro muda o mundo. Livros mudam pessoas que, com algum } \\
\text { esforço, tentam mudar o mundo. Para que isso aconteça, no entanto, é preciso que o livro } \\
\text { não apenas proponha uma nova maneira de pensar ou sentir, mas que chegue aos leitores } \\
\text { no momento certo - nem antes nem depois. Se } O \text { Segundo Sexo, clássico feminista de } \\
\text { Simone Beauvoir, tivesse sido escrito } 50 \text { anos antes, talvez nem chegasse às livrarias. } \\
\text { Cinquenta anos depois, teria causado pouco ou nenhum impacto. Em 1949, provocou uma } \\
\text { pequena grande revolução. } \\
\text { Quando se trata daquele mundinho íntimo formado pelas ideias ou sentimentos que } \\
\text { impactam as nossas vidas de forma marcante, funciona mais ou menos do mesmo jeito. } \\
\text { Temos que estar prontos para que livros (ou filmes, músicas, peças de teatro...) mudem as } \\
\text { nossas vidas - ou pelo menos criem a sensação de que isso aconteceu. Mas mesmo quem } \\
\text { gosta muito de ler não encontrará, ao longo de toda a vida, mais do que cinco ou seis } \\
\text { experiências capazes de provocar essa sensação de Queda da Bastilha interior. Um livro } \\
\text { que fique na memória não apenas pelo impacto estético que proporcionou, mas por causar } \\
\text { um tipo de curto-circuito que, ao contrário de apagar todas as luzes, ilumina. } \\
\text { Na segunda-feira à noite, quando começaram a chegar as notícias sobre a morte do } \\
\text { escritor norte-americano Robert M. Pirsig (1928-2017), autor de Zen e a Arte de } \\
\text { Manutenção de Motocicletas (1974), uma frase se repetia com alguma frequência nos } \\
\text { comentários dos seus leitores: "Este livro mudou a minha vida". Li o romance aos 19 anos } \\
\text { e nunca voltei a ele, mas também fui profundamente impactada pela história desse pai que } \\
\text { vai para a estrada, de moto, na companhia do filho de 11 anos, refletindo sobre aquilo que } \\
\text { alguns filósofos chamam de "a boa vida". } \\
\text { Numa interpretação muito singela, encontrar "a boa vida" é descobrir qual é a sua } \\
\text { no mundo e fazer o possível para não se perder muito nos atalhos. Aos 19 anos, não } \\
\text { poderia ter recebido um conselho mais decisivo. }\end{array}$ \\
\hline
\end{tabular}

Fonte: Zero Hora, 28 de abril de 2017, p. 4. 